\title{
Design and Optimization of the Housing of Spray Unit of a Linear Motor Operated Spray Gun
}

\author{
A. K. M. Parvezlqbal ${ }^{*}$, IshakAris ${ }^{2}$, M. M. Rahman ${ }^{1}$ and NorhisamMisron ${ }^{2}$ \\ 'Department of Mechanical Engineering, College of Engineering, Universiti Tenaga Nasional \\ (UNITEN), Jalan IKRAM-UNITEN, 43000, Kajang, Selangor, Malaysia; parvez@uniten.edu.my \\ ${ }^{2}$ Department of Electrical Engineering, Faculty of Engineering, Universiti Putra \\ Malaysia (UPM), 43400 UPM Serdang, Selangor, Malaysia
}

\begin{abstract}
Pneumatic system is normally used to trigger the automatic spray gun for conventional spray operations. Highly skilled labors and a number of adjustable knobs are required to produce the high quality coating works using the conventional automatic spray gun which is cost intensive. Therefore, linear motor operated multiple spray operations spray gun has been developed. This spray gun consists of two spray units, an air control and supply unit and a triggering unit to carry out the multiple spray operations. This paper focuses on the design optimization and fabrication of the housing of the spray units which hold fluid nozzles, air nozzles, an assembly cap, a needle valve or a ball valve. In the air less and air assisted airless spray systems, high pressurized liquid is passed through the nozzle which is held by the housing of the spray unit. Before entering into the nozzle, the high pressurized liquid is passed through the housing. For the simplicity of the analysis, it is assumed that the housing is an open-ended pressure vessel. From the analysis, dimensions and material selection have been optimized and finally the spray units have been fabricated and tested. During the performance test it is seen that satisfactory transfer efficiency of spray operation has been achieved by using newly developed spray housing of the spray units, which proves the stability of the spray housing during high pressure operation.
\end{abstract}

Keywords: Spray Gun, Spray Process, Design, Pressure Vessel, Failure Analysis, Deflection Analysis.

\section{Introduction}

The spray application of coating to protect and decorate products has undergone considerable change since it was initiated long time ago. The industrial revolution has given us an un-limited supply of new atomization tools and variety of coating materials to cover the surfaces for protection and decoration. Currently, there are four major processes of spray application, i.e., air atomization conventional air spray, high volume low pressure (HVLP) atomization, airless atomization and air assisted airless atomization [1-3]. A lot of researches were conducted in relation to the nozzle size prediction, optimization of flow patterns, determination of paint thickness, ergonomic studies of spray guns, operating mechanism of spray guns etc.

Colbert et al. [4] dealt with a computer simulation to predict electrostatic spray patterns. The main objective of this research was to predict the thickness of the coating and describe the accurate distribution to ensure uniformity. Automotive industries for metal coatings, agricultural industries for the reduction of the pest populations, and the pharmaceutical industries for charged inhalers, are extensively using the electrostatic spray process [5-7]. The ergonomic study of spray guns are also being carried out by the researchers to provide more comfort in handling the spray gun and to make the spray gun more commercially appealing [8,9]. Meanwhile, Markus et al. [10] analyzed the

*Corresponding author:

A. K. M. Parvezlqbal (parvez@uniten.edu.my) 
growth of deposits in spray forming with multiple atomizers. In this research, two overlapping sprays were involved. The mass flux and enthalpy distribution were examined for different spray conditions and overlapping angles of the two sprays. Normally, for large billets in industrial production, two free fall atomizers are used mainly because of the increased yield [11].

Another research was carried out by Nonnenmacher et al. [12] to design a hollow cone pressure swirl nozzle which could atomize Newtonian fluids. In this study they developed calculation models to foretell the drop size that depends on the hollow cone nozzle's geometry and volume flow for atomization of Newtonian fluids. In addition, atomization characteristics on the surface of a round liquid jet were investigated by Mayer et al. [13]. Liquid atomization quality is an important parameter of many technological processes such as in defining engine performance. This research investigates the jet performance for the single injector element to establish the influence of the injection conditions on a round liquid jet. Furthermore, a unified spray forming model used to predict the shape of the billet geometry had been developed. The developed model for atomization and the deposition processes have been joined together to get a new unified description of the spray forming process. The developed model can be used for predicting the contour and the temperature of a sprayformed billet [14]. Additionally, the CFD analysis for the electrostatic powder coating process with the corona spray gun has been carried out. This research found that the final spray pattern shape and the increase of transfer efficiency depended on the space charge [15]. Meanwhile, a test air induction nozzle was designed and manufactured to examine design parameters impact on the characteristics of the spray and how the spray characteristics influence the flow profile [16]. The interaction between air and liquid in the breakup zone of twin fluid atomization was investigated. The research was carried out by injecting the air with and without liquid [17].

Danny et al. [18] invented a portable self-contained power sprayer to produce a foam effluent spray from a liquid. The sprayer includes a segregated air and liquid delivery system that separately supply air and liquid to a mixing chamber. The mixing chamber may be configured within a flow controller. A pressure switch which is included in the control circuit is operatively connected to the liquid supply line to trigger the pump and compressor in maintaining the pressure within the liquid supply line. Another spray gun invented by Masahiko et al. [19] is used for electrostatic coating. Coating materials whose electric resistance is relatively low are used for this spray gun.

Matthew invented a spray gun which comprised a mixer of the catalyst and resin. The spray operation is carried out after the mixing. The catalyst is mixed with air before the catalyst/air mixture is introduced to the resin in the mixing tube. In order to prevent the resin and catalyst from back flowing into the air/catalyst supply line, a specially designed check valve is used for this sprayer [20]. A handheld apparatus for spraying texture material was invented by Craig et al. [21]. This sprayer comprises a body, a pressurized air source mounted on the body, a texture material hopper mounted on the body, and a texture delivery nozzle for selectively spraying texture material. During the coating operation, the texture material is propelled by the pressurized air. A hand-held dual nozzle spray gun was invented by Georgio [22]. This spray gun is used for applying an electroless plating solution. The spray gun is configured with a handle, a trigger connected to the handle, a first fluid passage, a second fluid passage, a switch, and a valve assembly. A modular spray gun was developed to operate selectable spray processes. This new spray gun consists of a gun body, an extension, and a selectable spray atomizing component. The basic gun body and extension are used to operate as an air spray gun, an airless spray gun, an AAA gun, or an HVLP spray gun. Circulation and non-circulating operations can be carried out using a modular extension. A variety of spray nozzle assemblies can be mounted to the modular extension for operating the desired spray process. An indicator device and/or relief valve is provided for spray guns using an HVLP spray process to ensure the maximum air pressure is less than $10 \mathrm{psi}$ [23].

From the above discussion, it can be concluded that there are still some areas on spray guns to improve their functionality. From that point of view, a linear motor operated multiple spray operations spray gun has been designed and developed [24-26]. This paper focuses only the design of the spray units, the analysis and optimization of the spray housing of the spray unit and the fabrication of the spray units.

\section{Methodology}

Instead of a pneumatic system, an especially designed linear motor is used to trigger the spray gun. Two spray units are used to fulfill the requirements of multiple spray operations without dismantling the internal system. The spray units can be rotated $90^{\circ}$ to either side. A single air control 
unit, an air control valve, and a triggering lever are used to carry out the spraying operation. All of the components are housed in a single gun body. During the spray operation, the spray unit is positioned by rotating the holder shaft. Once the spray unit is in position, it ensures that the rear end of the needle valve is inside of the passage of the triggering lever. After getting the position of the spray unit, the air flowpiping system is inserted into the spray unit by rotating the rear knob of the air control unit to protect the rotational movement of the spray unit. Now the sensorless DC linear motor is activated to produce thrust to the triggering lever and due to the pin joint, the lever moves backward by compressing the air valve spring, allowing air to flow into the system. Once the lever is displaced, it displaces the needle valve position, opening the nozzle so the spraying operation can be performed. For the air less spray system, the air supply is stopped. In order to execute the system, at least 7 bar to 9 bar air pressure and at least 6 bar liquid pressure are needed for the air spray system. For the air less system, at least 35 bar of fluid pressure is necessary. In order to execute the linear motor, at least $0.4 \mathrm{~A} \mathrm{DC}$ input current is necessary. Figure 1 shows the internal system of the linear motor operated spray gun.

As shown in Figures 2(a) and 2(b), the spray units comprise liquid nozzles, air nozzles, an assembly cap, a needle valve, a ball valve and housing. Two units of spray housing were designed for air spray and airless spray accordingly. Two units of spray housing were held to the spray gun body with a holder. The holder was attached at the holding place of the spray housing. Three air passages were provided in each housing to fulfill the requirement for the amount of air which was used for atomization. Four air releasing holes were provided to atomize the liquid according to the spray-

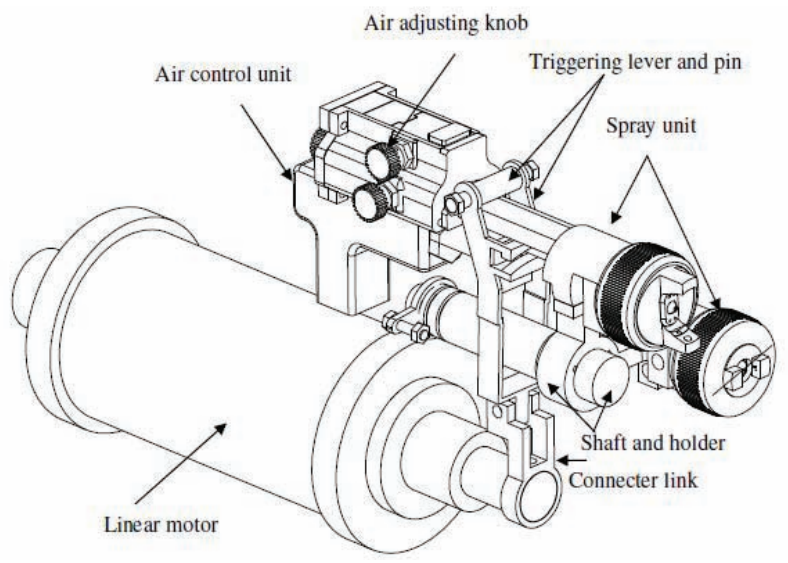

Figure 1. The internal system of linear motor operated spray gun. ing process. All of the features were similar in both units, but the configurations were different because the airless
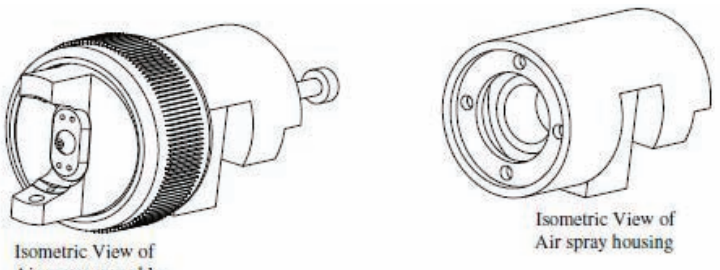

Air spray assembly
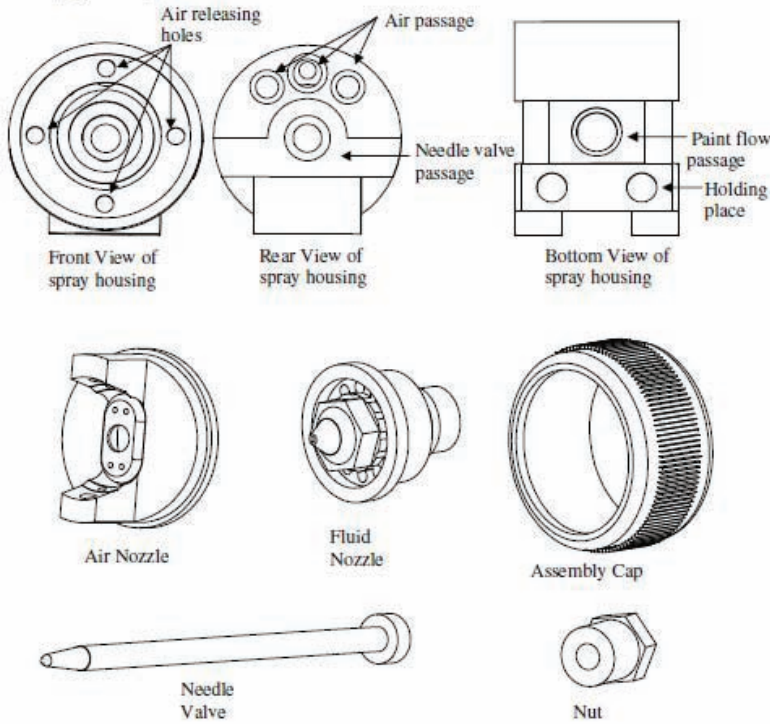

Nut

Figure 2(a). The spray unit of an air spray system.
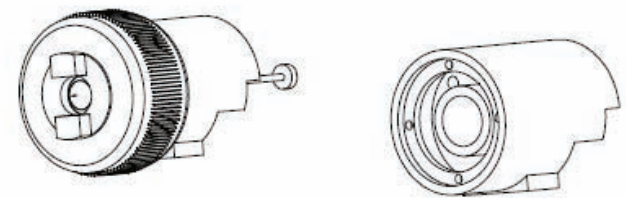

Isometric view of Airless spray assembly Isometric view of Airless spray housing
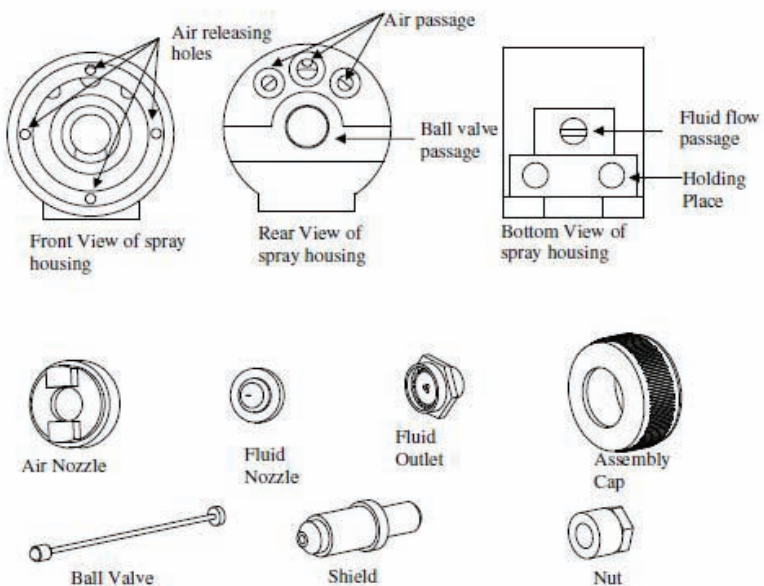

Figure 2(b). The spray unit of anairless spray system. 
system needed almost double the pressure compared to the air spray. The needle valve passage and ball valve passage were designed in such a way that these can hold the valves properly without leaking the liquid. The valves were kept through the passage with rubber shielded hollow nuts. To select the proper materials and dimensions of the spray housing, analyses were carried out by considering the spray housing as a pressure vessel. Deflection theory and failure theory can also be used in these analyses.

In the air less and air assisted airless systems, high pressurized liquid is passed through the nozzle which is held by the housing of the spray unit. Before entering into the nozzle, the high pressurized liquid is passed though the housing. Therefore it is important to analyze whether the housing can withstand the high pressure conditions. For the simplicity of the analysis, it is assumed that the housing is an open-ended pressure vessel, and the target of this analysis is to find the suitable material and thickness of the pressurized housing. The theory which governs this analysis is as follows:

When the ratio of the internal diameter to the thickness of the cylinder is less than 20 , they may be considered as thick cylinders. For the design of the thick cylinders, Lame's equation is used [27-30]. Referring to the Figure 3, if the inside radius of the cylinder is $r_{i}$, the outside radius is $r_{o}$, the internal pressure $p_{i}$, and the external pressure $p_{o}$, then it can be shown that tangential and radial stresses exist whose magnitude are written in Equations 1 and 2.

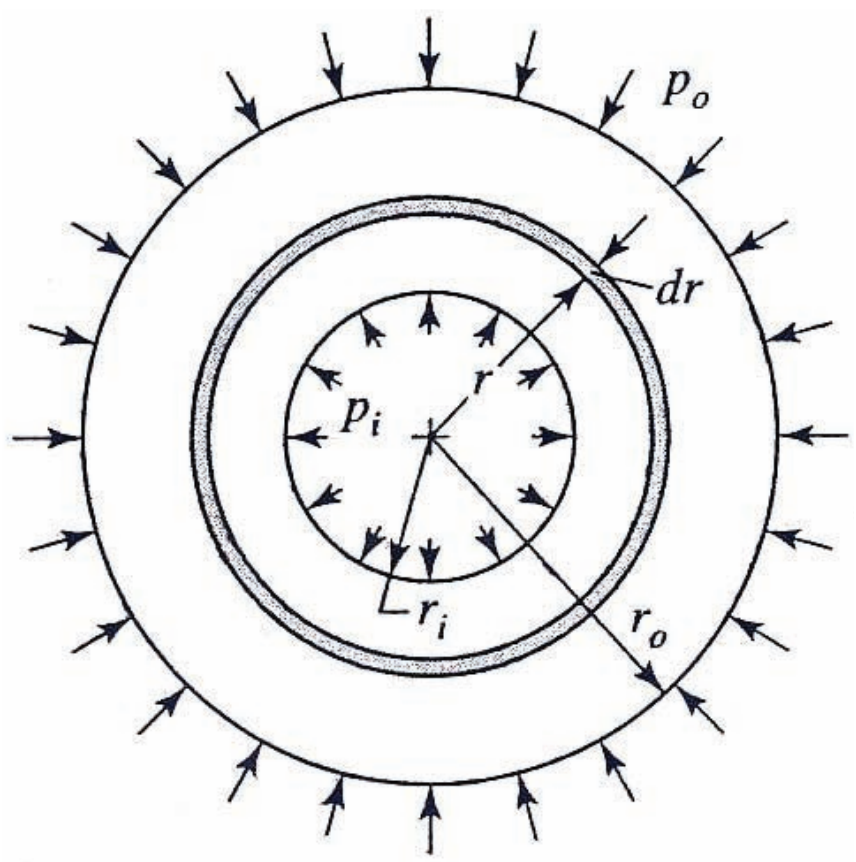

Figure 3. The pressure distribution of a pressure vessel.

$$
\begin{aligned}
\sigma_{t} & =\frac{p_{i} r_{i}^{2}-p_{o} r_{o}^{2}-r_{i}^{2} r_{o}^{2}\left(p_{o}-p_{i}\right) / r^{2}}{r_{o}^{2}-r_{i}^{2}} \\
\sigma_{r} & =\frac{p_{i} r_{i}^{2}-p_{o} r_{o}^{2}+r_{i}^{2} r_{o}^{2}\left(p_{o}-p_{i}\right) / r^{2}}{r_{o}^{2}-r_{i}^{2}}
\end{aligned}
$$

For this analysis $p_{0}=0$, therefore the tangential and redial stresses are shown in Equations 3 and 4.

$$
\begin{aligned}
& \sigma_{t}=\frac{r_{i}^{2} p_{i}}{r_{o}^{2}-r_{i}^{2}}\left[1+\frac{r_{o}^{2}}{r^{2}}\right] \\
& \sigma_{r}=\frac{r_{i}^{2} p_{i}}{r_{o}^{2}-r_{i}^{2}}\left[1-\frac{r_{o}^{2}}{r^{2}}\right]
\end{aligned}
$$

Substituting $r=r_{i}$ and $r=r_{o}$ in Equation 3 to obtain Equations 5 and 6 .

$$
\begin{gathered}
\sigma_{t}(\max )=\frac{p_{i}\left(r_{i}^{2}+r_{o}^{2}\right)}{r_{o}^{2}-r_{i}^{2}} \\
\sigma_{t}(\min )=\frac{2 p_{i} r_{i}^{2}}{r_{o}^{2}-r_{i}^{2}}
\end{gathered}
$$

Similarly substituting $r=r_{i}$ and $r=r_{o}$ in Equation 4 to obtain Equations 7 and 8.

$$
\begin{aligned}
& \sigma_{r}(\max )=-p_{i} \\
& \sigma_{r}(\min )=0
\end{aligned}
$$

To get an idea on which materials to select, it was necessary to investigate the maximum values of tangential and radial stresses, which can develop in the pressurized housing. Since the materials are ductile, according to Lame's equation the thickness of the housing is given by Equation 9 .

$$
t=r_{i}\left[\left\{\frac{\sigma_{t d}}{\sigma_{t d}-2 p_{i}}\right\}^{\frac{1}{2}}-1\right]
$$

Due to the use of ductile materials for analysis, maximum shear stress theory, and maximum distortion energy theory can be the optimum choice to predict the failure. According to these theories, failure can be protected if the following criteria are followed:

For maximum shear stress theory: $\begin{aligned} & \left|\sigma_{1}\right| \leq \sigma_{y} \\ & \left|\sigma_{2}\right| \leq \sigma_{y}\end{aligned}$ same signs

$\left|\sigma_{1}-\sigma_{2}\right| \leq \sigma_{y} \quad \sigma_{1}, \sigma_{2}$ have opposite signs

For maximum distortion energy theory: $\left(\sigma_{1}^{2}-\sigma_{1} \sigma_{2}+\sigma_{2}^{2}\right) \leq \sigma_{y}^{2}$ 
Where $\sigma_{1}$ and $\sigma_{2}$ are maximum principal stress and minimum principal stress, respectively and $\sigma_{y}$ is design yield stress. For this analysis, $\sigma_{1}=\sigma_{t}(\max )=\frac{p_{i}\left(r_{i}^{2}+r_{o}^{2}\right)}{r_{o}^{2}-r_{i}^{2}}$ and $\sigma_{2}=\sigma_{r}(\max )=-p_{i}$. By using the failure theory and the above equations, suitable and safe thickness of the pressurized housing can be selected.

To determine the suitable material among the selected materials, it was necessary to investigate their deflection of the same loading condition. The less deformed material will be selected for the pressurized housing. To carry out the analysis for deflection, the pressurized housing was divided longitudinally into 5 segments, and each segment was treated as a simply supported beam with a center loading.

Equations 13-15 are used to measure the deflections for a simply supported beam. The equations are shown below:

$$
\begin{gathered}
y_{A B}=\frac{F x}{48 E I}\left(4 x^{2}-3 l^{2}\right) \\
y_{\text {max }}=-\frac{F l^{3}}{48 E I} \\
y_{B C}=\frac{F a(l-x)}{6 E I l}\left(x^{2}+a^{2}-2 l x\right)
\end{gathered}
$$

Where $y_{A B}$ is the deflection in $\mathrm{m} ; y_{\max }$ is maximum deflection in $\mathrm{m} ; F$ is force in $\mathrm{N} ; l$ is total length of the beam in $\mathrm{m}$; $x$ is variable distance along the length $l$ in $\mathrm{m} ; E$ is modulus of elasticity in GPa and $I$ is the moment of inertial in $\mathrm{m}^{4}$.

\section{Result and Discussion}

In order to get an idea about selecting the materials, it was necessary to investigate the maximum values of tangential and radial stresses, which can be developed in the pressurized housing. The materials would be selected based on the design yield strength that must be higher than the calculated maximum tangential stress. Table 1 shows the maximum value of tangential and radial stresses, selected material and their corresponding calculated thickness.

From the Table 1 it is seen that in both cases almost the same thickness was found. In that situation, to get the suitable thickness, the failure theory for static load was used. Table 2 shows the results of thickness and their corresponding status using failure theories.

From the Table 2, it is seen that a thickness of $2.5 \mathrm{~mm}$ was just above the failure mode for both aluminium and brass material. Therefore, $3 \mathrm{~mm}$ or $3.5 \mathrm{~mm}$ will be the optimum thickness for both materials.
In order to select the material between $\mathrm{Al}$ and $\mathrm{Br}$ it was necessary to investigate their deflection of the same loading condition. The less deformed material will be selected for the pressurized housing. $4.543 \times 10^{-4} \mathrm{~m}^{2}$ of internal area and $18794.39 \mathrm{~N}$ of internal pressure were used to carry out the deflection analysis. In addition, the pressurized housing was divided longitudinally into 5 segments and each segment was treated as a simply supported beam with center loading.

From Figure 4, it is clearly seen that the deflection for aluminum was more than the brass, therefore brass was the optimum choice for this pressurized housing. The thickness of the pressurized housing was selected from the failure analysis.

Figure 5 shows the thickness and their corresponding deflection. It is clear that if the thickness is increased the deflection will decrease. From the failure theory it is proven that $3 \mathrm{~mm}$ is the safe minimum thickness and its corresponding deflection is near to zero.

\subsection{Fabrication of Spray Unit}

The spray unit is comprised of the liquid nozzle, air nozzle valve, nut and assembly cap. Among these components, the liquid nozzle and air nozzle used were standard commercial products and the spray housing, valve, nut and assembly cap were fabricated according to the design. Figures 6(a) and 6(b) show fabricated spray units of air spray and airless spray systems respectively.

The turning, boring, threading and milling operations were carried out to fabricate the spray housing for the air spray and airless spray systems using a lathe and a milling machine. The internal cylinder that was used to hold the fluid nozzle was assembled to the spray housing by press fitting. The turning operation was carried out to provide the proper shape of the spray housing, meanwhile the boring operation provided the fluid flow passage, and the air flow passage inside the spray housing. The milling operation was mainly carried out to develop the holding position of the spray housing. The thread was fabricated to hold the air and the fluid nozzles and the nut in the proper position. The valve was held in position with the help of the nut. Simple turning and grinding operations were carried out to fabricate the valve. Several tests were conducted for the air spray and airless spray systems. From this performance test, it was observed that the spray housing could withstand the required air and fluid pressure without any deflection and failure. Figures 7 (a) and 7(b) show fabricated 
Table 1. The maximum value of tangential and radial stresses, selected material and their corresponding calculated thickness.

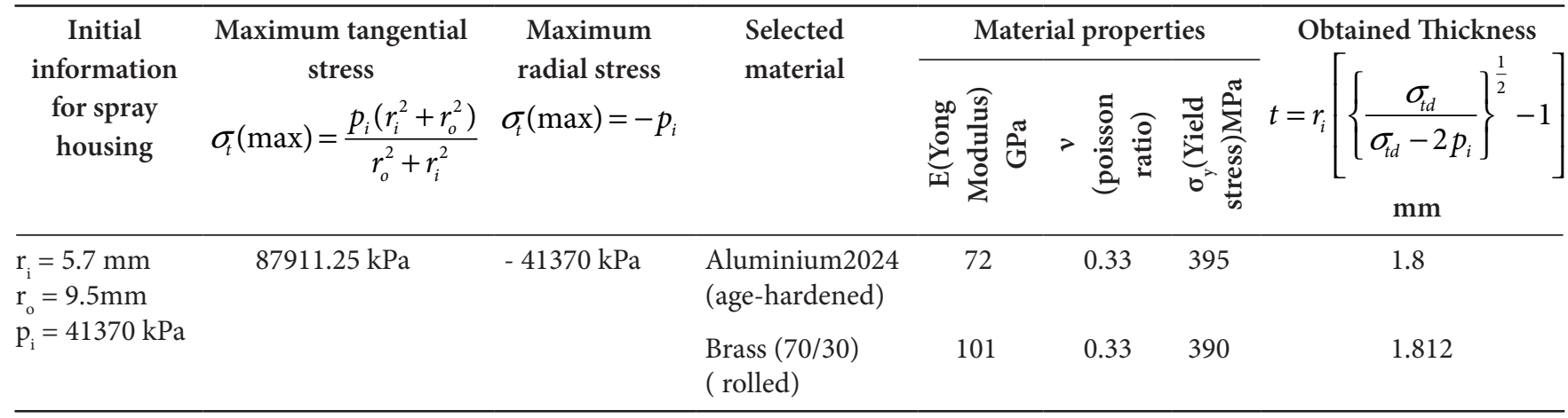

Table 2. The results of thickness and their corresponding status using failure theories.

\begin{tabular}{|c|c|c|c|c|c|c|c|c|c|}
\hline \multirow[t]{2}{*}{$\begin{array}{l}\text { Outside } \\
\text { radius, } \\
\mathrm{mm}\end{array}$} & \multirow[t]{2}{*}{$\begin{array}{l}\text { Thickness } \\
\text { mm }\end{array}$} & \multirow[t]{2}{*}{$\begin{array}{l}\text { Inside } \\
\text { radius, } \\
\mathrm{mm}\end{array}$} & \multirow[t]{2}{*}{$\begin{array}{c}\sigma_{1} \\
\mathrm{kN} / \mathrm{m}^{2}\end{array}$} & \multirow[t]{2}{*}{$\begin{array}{c}\sigma_{2} \\
\mathrm{kN} / \mathrm{m}^{2} \\
- \text { eve }\end{array}$} & \multicolumn{2}{|c|}{$\begin{array}{l}\text { Max shear stress theory } \\
\qquad\left|\sigma_{1}-\sigma_{2}\right| \leq \sigma_{y}\end{array}$} & \multicolumn{2}{|c|}{$\begin{array}{l}\text { Max distortion energy } \\
\text { theory }\left(\begin{array}{l}\sigma_{1}^{2}-\sigma_{1} \sigma_{2} \\
+\sigma_{2}^{2}\end{array}\right) \leq \sigma_{y}^{2}\end{array}$} & \multirow[t]{2}{*}{ Status } \\
\hline & & & & & $\begin{array}{l}\text { Aluminum } \\
\qquad \mathrm{MPa}\end{array}$ & $\begin{array}{l}\text { Brass } \\
\text { MPa }\end{array}$ & $\begin{array}{l}\text { Aluminum } \\
(\mathrm{MPa})^{2}\end{array}$ & $\begin{array}{l}\text { Brass } \\
(\mathrm{MPa})^{2}\end{array}$ & \\
\hline 9.5 & 1.8 & 7.7 & 199821 & 41370 & $241.2 \geq 197.5$ & $241.2 \geq 195$ & $\begin{array}{l}49906.50 \geq \\
39006.25\end{array}$ & $\begin{array}{l}49906.50 \geq \\
38025\end{array}$ & Fail \\
\hline 9.5 & 2 & 7.5 & 178256.03 & 41370 & $219.62 \geq 197.5$ & $219.62 \geq 195$ & $\begin{array}{l}40861.13 \geq \\
39006.25\end{array}$ & $\begin{array}{l}40861.13 \geq \\
38025\end{array}$ & Fail \\
\hline 9.5 & 2.5 & 7 & 139655.09 & 41370 & $181.025 \leq 197.5$ & $181.025 \leq 195$ & $\begin{array}{l}26992.52 \leq \\
39006.25\end{array}$ & $\begin{array}{l}26992.52 \leq \\
38025\end{array}$ & Safe \\
\hline 9.5 & 3 & 6.5 & 114198.44 & 41370 & $155.57 \leq 197.5$ & $155.57 \leq 195$ & $\begin{array}{l}19477.03 \leq \\
39006.25\end{array}$ & $\begin{array}{l}19477.03 \leq \\
38025\end{array}$ & Safe \\
\hline 9.5 & 3.5 & 6 & 96085.16 & 41370 & $137.46 \leq 197.5$ & $137.46 \leq 195$ & $\begin{array}{l}14918.84 \leq \\
39006.25\end{array}$ & $\begin{array}{l}14918.84 \leq \\
38025\end{array}$ & Safe \\
\hline 9.5 & 4 & 5.5 & 83084.75 & 41370 & $124.45 \leq 197.5$ & $124.45 \leq 195$ & $\begin{array}{l}12051.61 \leq \\
39006.25\end{array}$ & $\begin{array}{l}12051.61 \leq \\
38025\end{array}$ & Safe \\
\hline 9.5 & 4.5 & 5 & 73071.15 & 41370 & $114.44 \leq 197.5$ & $114.44 \leq 195$ & $\begin{array}{l}10073.79 \leq \\
39006.25\end{array}$ & $\begin{array}{l}10073.79 \leq \\
38025\end{array}$ & Safe \\
\hline
\end{tabular}

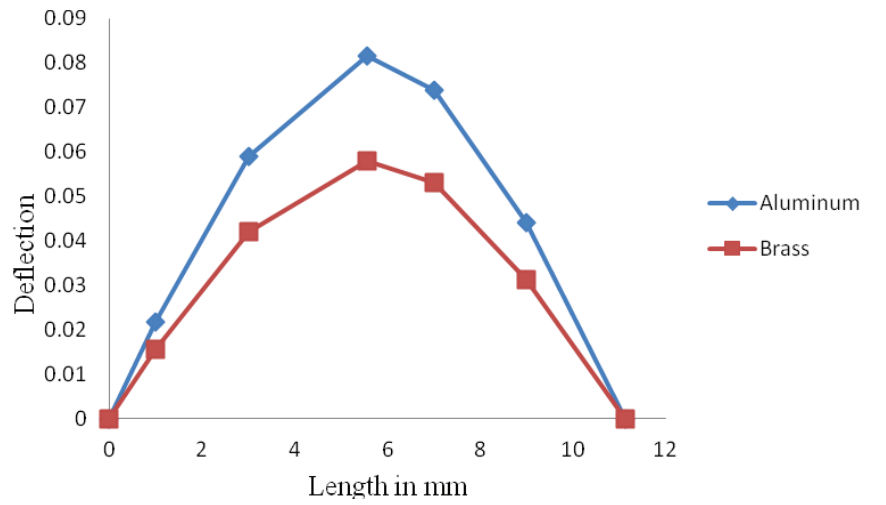

Figure 4. The length and corresponding deflection.

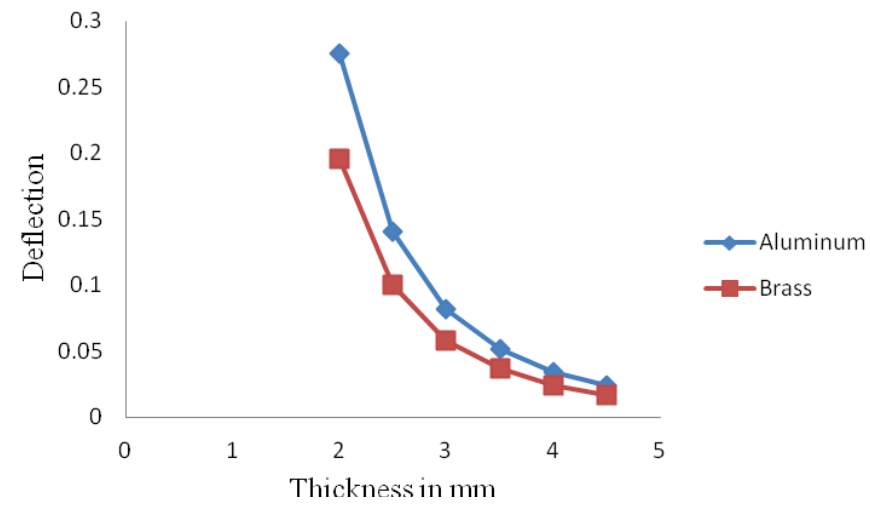

Figure 5. The thickness and corresponding deflection. 


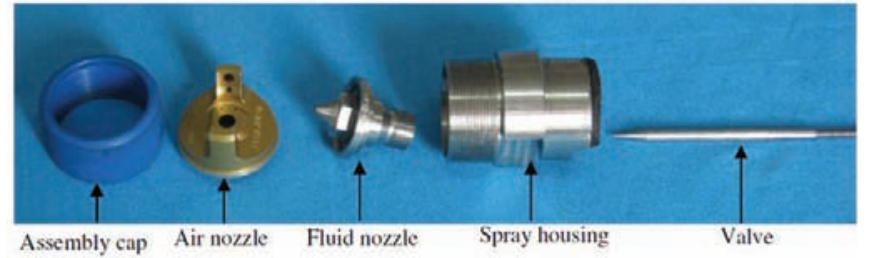

Figure 6(a). The fabricated spray unit of an air spray system.

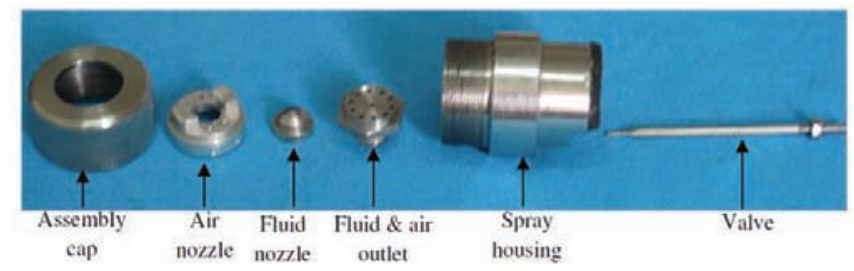

Figure 6(b). The fabricated spray unit of an airless spray system.

spray housing of the air spray and air less spray systems respectively.

\subsection{Testing Performance of the System in Air Spray and Airless Spray}

Figure 8 illustrates the variation of transfer efficiency of the air spray system with the changing of the input current and the target distance. The target distances were varied from $75 \mathrm{~mm}$ to $375 \mathrm{~mm}$. When the target distance was very close to the spray gun, at partially open nozzle, a higher transfer efficiency was obtained, but in the fully open condition it dropped down. For example, at $75 \mathrm{~mm}$ target distance, and $0.4 \mathrm{~A}$ input current a transfer efficiency was obtained of $20 \%$, but at $1.4 \mathrm{~A}$ input current, it was only $17 \%$. The reason was at $0.4 \mathrm{~A}$ input current, the nozzle was partially open, therefore the bounce back of the fluid was low. But at $1.4 \mathrm{~A}$ input current, the nozzle was fully open and the fluid was flown at the maximum flow rate and a higher kinetic energy, therefore the bounce back of the fluid was very high. When the target distance was too far from the spray gun, in the partially open nozzle condition, a very low transfer efficiency was obtained. Meanwhile, in the fully open condition, the transfer efficiency was increased, but it did not achieve the satisfactory level. For example at $0.4 \mathrm{~A}$ input current and at $375 \mathrm{~mm}$ target distance when the nozzle was partially opened, only $18 \%$ of transfer efficiency was obtained. On the other hand, at $1.4 \mathrm{~A}$ input current at the same target distance, a $23 \%$ of transfer efficiency was obtained. The reason was, in the partially open condition,

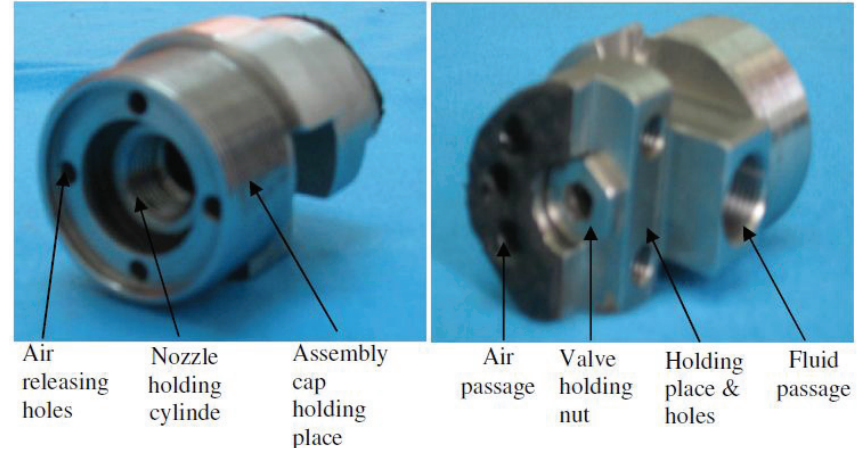

Figure 7(a). The fabricated spray housing of an air spray system.

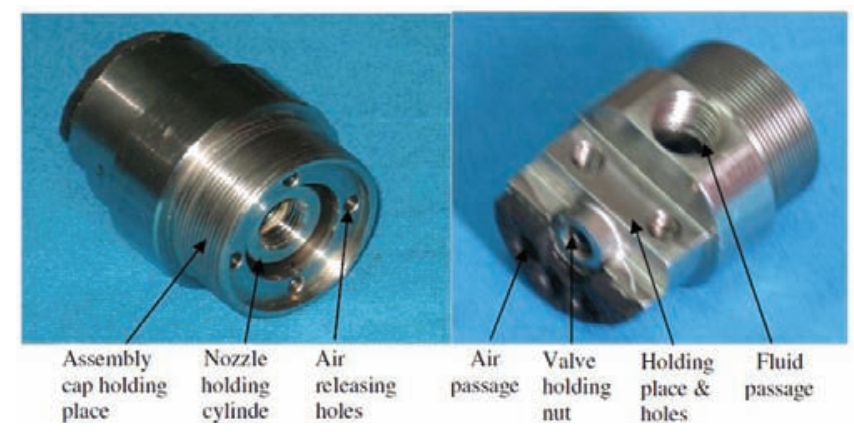

Figure 7(b). The fabricated spray housing of an airless spray system.

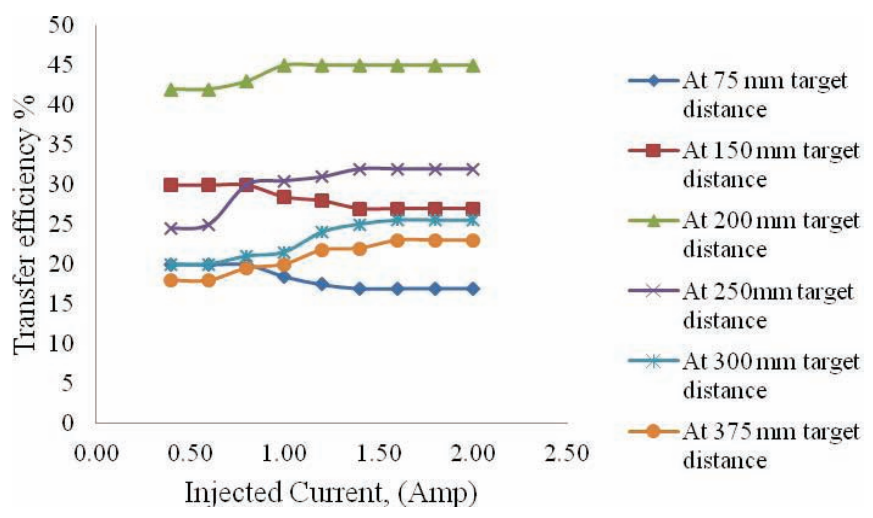

Figure 8. Transfer efficiency of different target position with input current.

the kinetic energy of the fluid was not enough to reach the target distance. On the other hand, in the fully open condition, the flow path became wider and the fluid flew away from the target distance. A satisfactory transfer efficiency of $45 \%$ was obtained at $200 \mathrm{~mm}$ target distance.

Figure 9 illustrates the input current and corresponding transfer efficiency when the target distance is nearer to the spray gun in the airless spray system. When the target 
distance was too close to the spray gun at a low pressure, and in the partially open nozzle condition, a higher transfer efficiency could be obtained. But in the same condition, when the nozzle is fully opened, the transfer efficiency dropped down. For example, at 35 Bar and $225 \mathrm{~mm}$ target distance, when the input current was $0.4 \mathrm{~A}, 50 \%$ of the transfer efficiency was achieved, but at the same distance and under the same pressure at $1.4 \mathrm{~A}$ current, the transfer efficiency dropped down to $43.5 \%$, because at $0.4 \mathrm{~A}$ current, the bounce back of the fluid was lower than at $1.4 \mathrm{~A}$ input current.

On the other hand, when the target distance was away from the spray gun as shown in Figure 10, the transfer efficiency increased as the input current increased, and obtained the maximum transfer efficiency in the fully open condition. But if the target distance was very far from the spray gun, a lower transfer efficiency was obtained. For

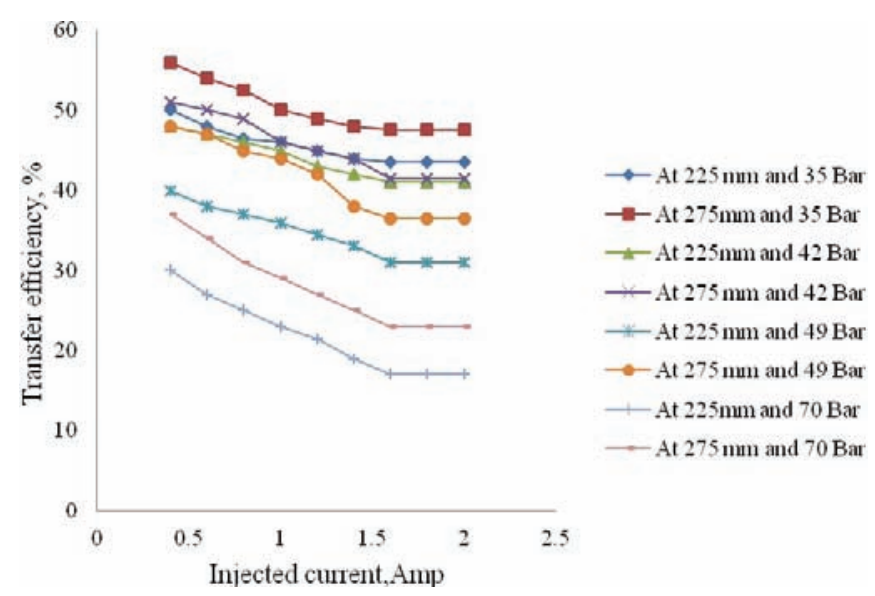

Figure 9. Transfer efficiency at nearer target distance of airless spray system.

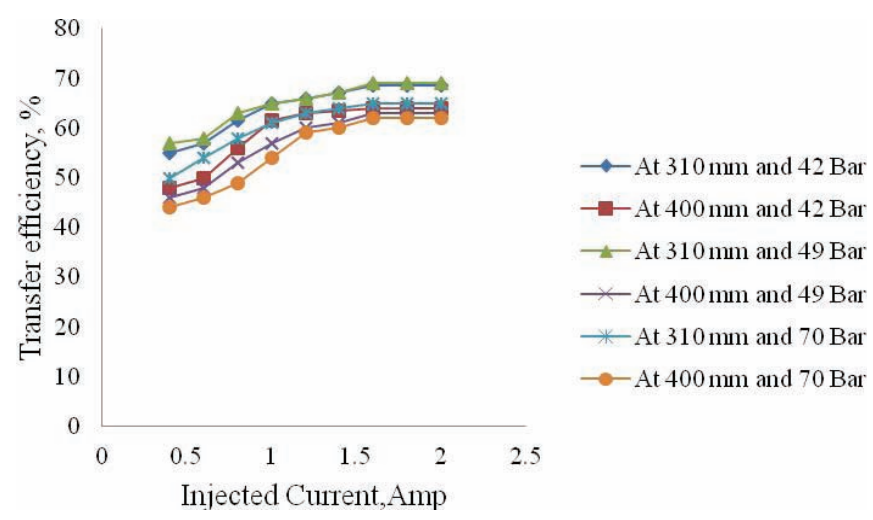

Figure 10. Transfer efficiency at other target distances of airless spray system. example, at $310 \mathrm{~mm}$ target distance and 35 Bar fluid pressure, when the current was varied from 0.4 to $1.4 \mathrm{~A}$, the transfer efficiency changed from $55 \%$ to $68.5 \%$. Further increases of the input current ranging from 1.4 to $2 \mathrm{~A}$ the transfer efficiency remained constant at $68.5 \%$. On the other hand, at $450 \mathrm{~mm}$ target distance and the same pressure and input current condition, the transfer efficiency changed from $45 \%$ to $63.5 \%$. After that, the transfer efficiency would remain constant even if the current was increased. The maximum transfer efficiency of $68.5 \%$ was achieved at 310 $\mathrm{mm}$ and $350 \mathrm{~mm}$ target distance when the fluid pressure was 35 Bar. Meanwhile, the maximum transfer efficiency of $68 \%$ was achieved at $350 \mathrm{~mm}$ target distance and 70 Bar of fluid pressure.

The total system was integrated and tested properly. For the air spray test, $45 \%$ of transfer efficiency at 200 $\mathrm{mm}$ target distance was achieved. From the literature, it is known that in the air spray system the transfer efficiency ranges from $30 \%$ to $60 \%$. The first prototype of this system achieved $45 \%$ of transfer efficiency. On the other hand, an airless test was also carried out. Different fluid pressures were used and every time, the flow rate, different target distance, and deposited flow rate were measured by changing the input current. A $68 \%$ to $69 \%$ of transfer efficiency was achieved at $310 \mathrm{~mm}$ and $350 \mathrm{~mm}$ target distance while the fluid pressure changed from 35 to 70 Bar. According to the literature, in the airless spray, the fluid pressure varies from 35 Bar to 310 Bar and transfer efficiency is obtained at $65 \%-70 \%$.

\section{Conclusion}

This paper has discussed the complete design and analysis of the spray unit of a linear motor operated multiple spray operations spray gun. CATIA software has been used to develop the model of the spray units. The spray housing of the unit has been considered as a thick walled pressure vessel therefore, thick walled pressure vessel theory has been used to obtain suitable materials for the spray housing. Failure theories for static loading condition (distortion energy theory and maximum shear stress theory) have been used to optimize the thickness of the spray housing. In order to obtain the optimized material, deflection analysis has been carried out by using simply supported beam formulae. Finally spray units have been fabricated according to the design and tested their performance. By using newly developed spray housings, satisfactory transfer efficiency has been achieved. 


\section{Acknowledgement}

The author would like to acknowledge Universiti Tenaga Nasional (UNITEN) to allow him to carry out this research by providing the technical supports. The author would like to Acknowledge the Institute of Advanced Technology (ITMA) and Faculty of Engineering of Universiti Putra Malaysia for providing the equipment and tools.

\section{References}

1. Hund, J P (1995). Spray application processes. JPH finishing consultants, 181-197.

2. Brajdich T, Hagman M et al. (1995). Atomization- Concept and theory training GRACO, 1-16.

3. Lefebvre A H (1989). Atomization and spray, Chapter 2, New York: Hamisphere publishing corporation, 105-150.

4. Colbert S A, and Cairncross R A (2005). A computer simulation for predicting electrostatic spray coating patterns, Powder Technology, vol 151(1-3), 77-86.

5. Meesters G M, Zevenhoven C A P et al. (1990). Fast computer simulation of open-air electrostatic spray painting, Journal of Electrostatics, vol 25, 265-275.

6. Bologa A M, and Makalsky L M (1989). Electrostatic pneumatic sprayer of water solutions, Journal of Electrostatics, vol 23, 227-233.

7. Bailey A G, Hashish A H et al. (1998). Drug delivery by inhalation of charged particles, Journal of Electrostatics, vol 44, 3-10.

8. Bjoring, G., \& Hagg, G. M. (2000). The ergonomics of spray guns-User's opinions and technical measurements on spray guns compared with previous recommendations for hand tools, International Journal of Industrial Ergonomics, vol 25, 405-414.

9. Lee, C. C, Nelson, J. E., Davis, K. G.,\&Marras, W.S. (1997). An ergonomic comparison of industrial spray paint guns. International Journal of Industrial Ergonomics, 19, 425-435.

10. Markus S, and Fritsching C C U (2004). Analysis of deposit growth in spray forming with multiple atomizers, Materials Science and Engineering A, vol 383, 166-174.

11. Nasr G G, Yule A J et al. (2002). Industrial sprays and atomization, Chapter 3, New York: Springer Verlag, 35-64.

12. Nonnenmacher S and Piesche M (2000). Design of hollow cone pressure swirl nozzle to atomize Newtonian Fluids, Chemical Engineering Science, vol 55(19), 4339-4348.

13. Mayer W O H, and Branam R (2004). Atomization characteristics on the surface of a round liquid jet, Experiments in Fluids, vol 36, 528-539.
14. Hattle J H, and Pryds N H (2004). A unified spray forming model for the prediction of billet shape geometry, Acta Materialia, vol 52(18), 5275-5288.

15. Ye Q, Steigleder T et al. (2002). Numerical simulation of the electrostatic powder coating process with a corona spray gun, Journal of Electrostatics, vol 54(2), 189-205.

16. Ellis M C B, Swan T et al. (2002). Design Factors affecting spray characteristics and drift performance of air induction nozzles. Biosystem Engineering, vol 182(3), 289-296.

17. Shavit U (2001). Gas-liquid interaction in the liquid breakup region of twin fluid atomization, Experiments in Fluids, vol 31(5), 550-557.

18. Jacque D R, Heethius B E et al. (2010). Portable powered foaming sprayer, United States Patent, Patent No. US7753290.

19. Amari M, Murata M et al. (2010). Electrostatic coating spray gun, United States Patent, Patent No. US7748651.

20. Merchant M (2010). Spray gun, United States Patent, Patent No. US7744019.

21. Peterson C, Torntore A J et al. (2010). Texture sprayer, United States Patent, Patent No. US7731104; 2010.

22. Roumanis G (2010). Hand held dual nozzle spray gun and system, United States Patent, Patent No. US7726589.

23. Hartle R J, Mancini D L et al. (2002). Modular fluid spray gun, United States Patent, Patent No. 6460787B.

24. Parvez I, Aris I et al. (2011). Thrust analysis and measurement of a tubular linear permanent magnet motor in spray application, Journal of Japan Society of Applied Electromagnetics and Mechanics, vol 19(S), S83-S86.

25. Parvez I, Aris I et al. (2011). Design process involved in developing mechanism of linear motor operated multiple spray operations spray gun, Australian Journal of Basic and Applied Sciences, vol 5(7), 843-850.

26. Parvez I, Aris I et al. (2011). Analysis of thrust constant, electrical and mechanical time constant of a tubular linear permanent magnet motor in spray application, $8^{\text {th }}$ International Symposium on Linear Drives for Industry Application, Netherland.

27. Sigley J E and Mischke C R (2003). Mechanical engineering design, $6^{\text {th }}$ Edn., Chapter 4, New York: McGraw Hill, 178-200.

28. Hamrok J B, Schmid S R et al. (2006). Fundamental of machine elements, $3^{\text {rd }}$ Edn., Chapter 6, New York: McGraw Hill, 235-250.

29. Jalaludeen S M (2000). Machine design, Kanpur, India: Anuradha Agencies, Chapter 3, 31-45.

30. Hibbeler R C (2005). Mechanics of Materials, $6^{\text {th }}$ Edn, Chapter 5, New York: Prentice Hall, 185-228. 